ARTIGO

\title{
O CORPO NA SOCIEDADE DE CONSUMIDORES: INTERPRETAÇÕES A PARTIR DE ESTUDANTES DO COLÉGIO PEDRO II
}

\author{
EL CUERPO EN LA SOCIEDAD DE CONSUMIDORES: INTERPRETACIONES DE \\ ESTUDIANTES DEL COLÉGIO PEDRO II
}

\author{
THE BODY IN THE CONSUMER SOCIETY: INTERPRETATIONS FROM STUDENTS \\ AT COLÉGIO PEDRO II
}

\author{
Guilherme de Castro Ribeiro Ferreira e Silva \\ Colégio Pedro II - Brasil \\ Ivan Marcelo Gomes \\ Universidade Federal do Espírito Santo - Brasil
}

Leonardo Trápaga Abib

Universidade Federal do Espírito Santo - Brasil

Resumo: O objetivo da pesquisa foi analisar as representações corporais de um grupo de estudantes do Ensino Médio do Colégio Pedro II. A pesquisa se desenvolveu com 77 estudantes do Ensino Médio regular e integrado do Colégio Pedro II - Campus São Cristóvão III. Os instrumentos para coleta de informações foram um questionário survey on-line e grupo focal, com análise baseada no Método de Interpretação dos Sentidos, privilegiando o diálogo com a abordagem sociológica de Zygmunt Bauman. As análises desenvolvidas demonstraram, em consonância com o argumento baumaniano em torno dos processos de privatização e consumo, que os estudantes possuem identidades corporais ambivalentes, ou seja, seus entendimentos sobre o corpo são fluidos em função das estratégias de responsabilização individual em torno das decisões sobre o corpo, que foram influenciadas, no escopo dessa pesquisa, por ações educativas presentes na instituição em foco e por influências midiáticas.

Palavras-chave: Adolescência. Corpo. Consumo.

\begin{abstract}
The purpose of the research was to analyze the body representations of a group of high school students at Colégio Pedro II. The study was carried out with 77 students from regular and integrated high school at Colégio Pedro II - Campus São Cristóvão III. The tools used for data collection were an online survey questionnaire and focus group, with analysis based on the Meaning Interpretation Method, privileging the dialog with the sociological approach of Zygmunt Bauman. The developed analysis showed, in line with the baumanian argument surrounding privatization and consumption processes, that students have ambivalent bodily identities, in other words, their understandings about the body are fluid, due to individual accountability strategies around decisions about the body, which were influenced, in the scope of this research, by educational actions present in the institution in focus and by media influences.
\end{abstract}

Keywords: Adolescence. Body. Consumption. 
Resumen: El objetivo de la investigación fue analizar las representaciones corporales de un grupo de estudiantes de secundaria del Colégio Pedro II. La investigación se llevó a cabo con 77 estudiantes de secundaria regular e integrada del Colégio Pedro II - Campus São Cristóvão III. Los instrumentos para la recolección de información fueron un cuestionario de encuesta en línea y un grupo focal, con análisis basado en el Método de Interpretación de los Sentidos, privilegiando el diálogo con el enfoque sociológico de Zygmunt Bauman. Los análisis desarrollados demostraron, en línea con el argumento baumaniano sobre los procesos de privatización y consumo, que los estudiantes tienen identidades corporales ambivalentes y sus entendimientos sobre el cuerpo son fluidos en función de las estrategias de responsabilidad individual en torno a decisiones sobre el cuerpo, los cuales fueron influenciados, en el ámbito de esta investigación, por acciones educativas presentes en la institución en foco y por influencias mediáticas.

Palabras clave: Adolescencia. Cuerpo. Consumo.

\section{O CORPO NA SOCIEDADE DE CONSUMIDORES NA LEITURA DE ZYGMUNT BAUMAN}

A sociedade de consumidores é caracterizada pela necessidade de descartar e de substituir. Para isso, ela conta com duas estratégias: a primeira é desvalorizar e depreciar os produtos de consumo com rapidez, e a segunda é "satisfazer" as necessidades/desejos/vontades de modo que nunca deixe de provocar novas expectativas nos sujeitos (BAUMAN, 2007). Nesse sentido, a sociedade de consumidores abre um leque de opções, ou como argumenta Bauman de modo metafórico: um supermercado com as mais diversas e variadas identidades corporais e possibilidades de cuidados para o corpo (BAUMAN, 2001).

Nessa perspectiva, o corpo consumidor é, antes de tudo, um receptor e colecionador de sensações, de necessidades/desejos/vontades sempre crescentes e nunca satisfeitas (BAUMAN, 2011). Para se adequar a essa norma, o corpo deverá estar sempre em boa forma, ou seja, ele deverá ser flexível, absorvente e ajustável, pronto para viver sensações ainda não testadas e impossíveis de descrever de antemão (BAUMAN, 2001).

Bauman (2001, p. 92) argumenta ainda que “[...] a vida organizada em torno da busca pela boa forma promete uma série de escaramuças vitoriosas, mas nunca o triunfo definitivo", pois os objetivos podem ser estabelecidos apenas para a presente etapa do esforço sem fim e a satisfação de "alcançar" o objetivo será fluida e apenas momentânea. A busca pela boa forma “[...] é um estado de autoexame minucioso, de autorrecriminação e autodepreciação permanentes, e assim, também de ansiedade contínua" (BAUMAN, 2001, p. 93). O corpo do consumidor é fonte de prazer, mas também de insegurança, de incerteza e de ansiedade, muito em função do mercado consumidor e de especialistas que fabricam desejos e que geram ansiedade e frenesi em torno dos cuidados com o corpo (BAUMAN, 2011). 
Diante desse cenário, observa-se um crescimento nos últimos anos do número de pesquisas que abordam a temática do corpo, principalmente em relação à juventude em idade escolar (ANDRADE et al., 2007; BRAGA; MOLINA; FIGUEIREDO, 2010; PALMA et al., 2013; PASSOS et al., 2013; FORTES et al., 2014; MARQUES et al., 2016). Os estudos listados destacam que existe um alto índice de jovens em idade escolar insatisfeitos com o corpo, com destaque para uma maior insatisfação entre as adolescentes, que, segundo as pesquisas, está mais associada ao "excesso" de peso. Outro ponto que se destaca entre os jovens é a predominância da representação na qual um corpo belo é aquele definido e forte (musculoso) para os meninos e o corpo magro e com curvas para as meninas. Para Andrade et al. (2007) existe uma necessidade de estabelecer um maior diálogo e reflexão juntos aos jovens no ambiente escolar sobre as questões que envolvem o corpo e como esse se insere na atual sociedade contemporânea.

Partimos da premissa que devemos considerar a juventude em sua pluralidade e diferença, o que implica, em primeiro lugar, compreender que os critérios que a compõe não mais devem ser tomados como únicos ou rígidos como em outrora, e sim mutáveis e construídos a partir das relações e experiências dos jovens dentro de seu próprio contexto social (DAYRELL, 2003). Em segundo lugar, a juventude não se trata de um período temporal com fim predeterminado, como a fase da crise ou do trânsito entre a infância e a vida adulta, pois, como os jovens são sujeitos plurais e vivem em diferentes contextos sociais e culturais, o processo nem sempre será linear (DAYRELL, 2003). São essas características presentes na juventude que têm despertado a atenção dos pesquisadores para a temática do corpo jovem, sobretudo pela transitoriedade e intensa mudança corporal que marcam essa fase (DAYRELL, 2003).

A partir das questões levantadas por esses trabalhos, construímos uma investigação cujo objetivo central é analisar as representações sobre o corpo apresentadas por um grupo de estudantes do Ensino Médio do Colégio Pedro II - Campus São Cristóvão III. O texto a seguir está estruturado em três seções: na primeira, apresentamos o campo de pesquisa e as estratégias metodológicas; na segunda, serão abordados os elementos referentes às concepções e às representações de corpo segundo os estudantes pesquisados; na terceira, faremos uma breve discussão acerca da relação entre corpo e mídia na construção das representações corporais dos estudantes. 


\section{CAMPO DE PESQUISA E ESTRATÉGIAS METODOLÓGICAS}

A pesquisa foi desenvolvida com 77 estudantes $^{1}$ (escolhidos aleatoriamente -53 meninas e 24 meninos $^{2}$ ) que no momento da investigação cursavam o Ensino Médio no Colégio Pedro II (CPII) - Campus São Cristóvão III (SCIII), situado no bairro de São Cristóvão na cidade do Rio de Janeiro. Este Colégio foi equiparado aos Institutos Federais de Educação, Ciência e Tecnologia, com a sanção da Lei 12.677/12 e conta com sete Campi, sendo cinco no município do Rio de Janeiro (São Cristóvão, Tijuca, Engenho Novo, Humaitá e Realengo), um em Niterói e um em Duque de Caxias. Com quase 13 mil estudantes, o CPII oferece turmas desde a Educação Infantil até o Ensino Médio Regular e Integrado, além da Educação de Jovens e Adultos (Proeja), Graduação e Pós-graduação lato e stricto sensu.

O Campus SCIII, local da pesquisa, criado em 1999, contava, no ano em que o estudo foi desenvolvido, com 39 turmas no Ensino Médio. Dessas, 15 eram do primeiro, 13 do segundo e 11 do terceiro ano. O corpo discente era formado por 1.400 estudantes das mais variadas áreas que compõem a região metropolitana do Rio de Janeiro.

Em relação à parte metodológica, o trabalho se caracteriza por ser uma pesquisa do tipo survey $^{3}$ exploratória (RICHARDSON, 1999), e a coleta de informações se dividiu em dois momentos, assim como os instrumentos utilizados: questionário survey on-line e grupo focal. A análise das questões discursivas do survey e do grupo focal se deu pelo Método de Interpretação de Sentidos (GOMES et al., 2005; MINAYO, 2006; GOMES, 2009).

A pesquisa do tipo survey exploratória caracteriza-se pela busca na obtenção de dados ou informações sobre características, ações ou opiniões de determinado grupo de pessoas, utilizando como instrumento de pesquisa, normalmente, um questionário on-line (WALTER, 2013). O instrumento utilizado para essa etapa do estudo foi o SurveyMonkey®, ferramenta gratuita para a construção de pesquisas do tipo survey. O questionário foi dividido em uma parte inicial em que constava o Termo de Consentimento Livre e Esclarecido (TCLE) e dados

\footnotetext{
${ }^{1}$ Os estudantes do questionário survey on-line e grupo focal serão identificados pelas letras iniciais do nome e idade, enquanto os estudantes que não se identificaram serão identificados por nomes fictícios e idade, quando disponibilizados.

${ }^{2}$ Inicialmente, elaboramos uma lista com todos os 1.400 estudantes do Campus (1.400), ordenados por ano escolar e sexo e identificados por seus e-mails fornecidos pela Secretaria do CPII - Campus SCIII. Dentre esses 1.400 estudantes, 228 (228) foram selecionados de forma aleatória simples para compor a amostra, sendo 114 meninas e 114 meninos. Desses 228 estudantes, 77 - 53 meninas e 24 meninos - responderam ao survey on-line.

${ }^{3}$ A escolha se deu pela necessidade de acessar os estudantes remotamente durante a greve no Colégio Pedro II, que se iniciou em 28 de outubro de 2016 e se estendeu até o dia 26 de dezembro de 2016, inviabilizando qualquer contato ou aplicação de questionário presencial.
} 
pessoais (nome, idade, sexo, município, bairro, ano escolar e dados socioeconômicos) e uma segunda parte específica, com questões objetivas e outras discursivas sobre a temática do corpo.

Com a intenção de potencializar e dar mais profundidade às informações obtidas no questionário do tipo survey, escolhemos o grupo focal como segundo instrumento de coleta de informações. O grupo focal foi elaborado com base nas questões que nortearam o questionário survey, bem como o estudo sistemático de artigos que tratavam do instrumento metodológico, como sua elaboração e aplicação (TRAD, 2009). Participaram do grupo focal sete estudantes ${ }^{4}$ (dois meninos e cinco meninas), e o roteiro de questões que norteou as discussões no grupo focal se articulou com o objeto do estudo, como o culto ao corpo e a pressão exercida pelos meios de comunicação em massa, sociedade, família e escola no que tange aos padrões corporais (identificados nas informações obtidas a partir do questionário survey).

O método escolhido para a análise de todo o material discursivo da pesquisa foi a Análise Interpretativa dos Sentidos (GOMES et al., 2005; MINAYO, 2006; GOMES, 2009). O método é uma "[...] perspectiva das correntes compreensivas das ciências sociais que analisa: palavras; ações; conjunto de inter-relações; grupos; instituições; conjunturas, dentre outros corpos analíticos" (GOMES et al., 2005, p. 202). Além disso, Minayo (2006) estabelece alguns princípios para o Método de Interpretação dos Sentidos: buscar lógica interna dos fatos, dos relatos e das observações; situar os fatos, os relatos e as observações no contexto dos atores; e produzir o relato dos fatos em que seus atores neles se reconheçam.

Em nossa pesquisa, utilizamos o seguinte caminho para a interpretação das informações a partir do Método de Interpretação dos Sentidos:

a) leitura compreensiva do material selecionado: essa etapa buscou compreender as informações gerais e específicas presentes em cada resposta dos estudantes, servindo para a construção da estrutura que seria a base de nossa interpretação. A estrutura para análise das informações foi dividida em duas categorias:

- corpo, mercado e mídia;

- corpo e serviços estéticos;

b) exploração do material: esse momento foi guiado pelos princípios da identificação (recorte e organização de trechos do depoimento e falas dos estudantes nas categorias

\footnotetext{
${ }^{4}$ Os critérios adotados para a escolha dos participantes visaram dar voz à multiplicidade de olhares sobre o objeto pesquisado. Além disso, levamos em consideração as reflexões mais elaboradas e consistentes feitas pelos estudantes nas diferentes questões discursivas do questionário survey identificadas a partir do Método de Interpretação dos Sentidos.
} 
apresentadas acima) e problematização das ideias explícitas e implícitas nos depoimentos e falas;

c) busca de sentidos mais amplos (socioculturais) atribuídos às ideias a partir das seguintes perguntas: as ideias se diferenciam? Existem ideias comuns? Há contradições nos depoimentos e falas dos estudantes?; diálogo entre as ideias problematizadas, informações provenientes de outros estudos acerca do tema e o referencial teórico do estudo (GOMES, 2009);

d) elaboração de síntese interpretativa: por fim, enquanto nas etapas anteriores organizamos e decompomos as informações do estudo, nessa etapa elaboramos uma síntese a partir do diálogo e da triangulação entre os objetivos do estudo, a base teórica adotada e os dados empíricos (GOMES, 2009).

Após o trabalho de produção e a análise dos dados oriundos do trabalho de campo, foram construídos para este texto dois eixos interpretativos:

a) relações entre corpo e sociedade de consumo a partir do olhar dos estudantes do CPII, na qual apresentamos nossas análises e discussões a respeito das percepções dos estudantes acerca do corpo no contemporâneo;

b) relações entre corpo e mídia a partir da percepção dos estudantes do CPII, em que apresentamos e refletimos brevemente a respeito das falas e comentários dos estudantes em relação ao papel dos meios de comunicação na construção das representações corporais no mundo contemporâneo.

\section{RELAÇÕES ENTRE CORPO E SOCIEDADE DE CONSUMO A PARTIR DO OLHAR DOS ESTUDANTES DO CPII}

$\mathrm{Na}$ presente seção, apresentaremos as análises dos dados obtidos por meio do questionário survey e do grupo focal. Para compor o escopo desta discussão, estabelecemos um diálogo entre os dados quantitativos e qualitativos com a teoria baumaniana.

$\mathrm{Na}$ introdução deste artigo, apresentamos diferentes pesquisas que têm o corpo jovem como objeto de estudo, principalmente relacionados à imagem corporal e níveis de satisfação/insatisfação com o corpo entre jovens escolares. Os estudos apontam para um índice elevado de insatisfação corporal entre os jovens escolares, fato que num primeiro momento ocorreu de maneira distinta em nossa investigação, em que mais da metade dos estudantes que participaram relataram gostar de seus corpos (73\%), enquanto que $27 \%$ responderam não gostar de seus corpos. 
Num segundo momento, levamos esse dado para ser discutido com os estudantes que participaram do grupo focal, para compreender o posicionamento e a percepção deles em relação ao tema. Como adiantamos, a relação que os estudantes estabelecem com o corpo na atual sociedade dos consumidores (BAUMAN, 2008a) é complexa e possui vários prismas e, por isso, precisamos jogar luz a diferentes entendimentos e falas presentes na pesquisa.

Durante o grupo focal, a estudante C.A. (15 anos) fez o seguinte comentário: "De qualquer forma, eu me surpreendo porque muita gente diz que sim (sobre gostar do próprio corpo), mas não é isso que a gente vê aí fora. E eu acho que isso acontece porque muitas pessoas têm vergonha de dizer que não estão satisfeitas com seu corpo". Questionados sobre a fala da colega, os estudantes do grupo focal disseram que também ficaram intrigados com o resultado, pois a sensação é a mesma que a de C.A. (15 anos). Para A.C. (16 anos), "As pessoas, às vezes, têm vergonha de dizer que não gostam do corpo, acho que por medo de serem julgadas", enquanto R.L. (19 anos) complementa: “Acho muito difícil gostar do próprio corpo quando a quase todo o momento você é confrontado e convencido do contrário".

O sentimento de insatisfação corporal gera vergonha e medo, e esses sentimentos são típicos da sociedade contemporânea (BAUMAN, 2011). Isso se vincula à noção de que a juventude é permeada por transformações, é uma etapa da vida cheia de descobertas, emoções e conflitos, bem como é uma fase marcada pelas experimentações em todas as dimensões da vida subjetiva e social. É também na juventude que as mudanças corporais assumem papel importante na vida do jovem, seja por preocupação com a própria aparência ou com o peso corporal (DAYRELL, 2014), como podemos observar nas falas dos estudantes quando perguntados no questionário survey como se sentem em relação aos seus corpos:

Porque gostaria de melhorar um pouco mais meu porte físico, me acho abaixo do peso e gostaria de reverter isso. (M.S., 18 anos).

Por estar acima do peso, não me sinto feliz, pois não posso usar algumas roupas, e isso me deixa insegura em alguns momentos. (C.B., 17 anos).

Porque é o corpo que tenho. Acredito que devemos nos amar como somos, mesmo sabendo da dificuldade que toda a pressão da mídia causa nas pessoas para que sejam perfeitas. (T.S., 19 anos).

Portanto, os jovens demonstram que vivem e convivem a partir de diferentes representações e vivências corporais, que vão além do discurso libertário ou daquele alinhado ao consumo, ou seja, suas representações e vivências são ambivalentes ${ }^{5}$ (BAUMAN, 1999).

\footnotetext{
5 Ambivalência na linguagem baumaniana representa a dificuldade que enfrentamos em nomear, classificar, ordenar, dar sentido ao mundo. Em outras palavras, a ambivalência é uma desordem (diferença e pluralidade). $\mathrm{O}$
} 
Dessa forma, a existência corporal que se apresenta se dá a partir da relação dialógica entre os medos, as tensões e as rupturas presentes no cotidiano de cada estudante, desaguando no que Bauman (1999) caracteriza como privatização da ambivalência. Diferente de outrora, quando o Estado nomeava, classificava e ordenava em quais identidades os sujeitos deveriam se adequar, na sociedade contemporânea a diferença e a pluralidade foram privatizadas, individualizando, dessa forma, a vida social, na qual cada sujeito é responsável pela (re)construção de suas identidades, bem como responsável pelas suas escolhas, sucessos e fracassos, e isso inclui o corpo (BAUMAN, 1999).

Ao realizar a análise a partir do recorte por sexo, observamos uma aproximação com os resultados de outras pesquisas que demonstraram haver maior grau de insatisfação corporal por parte das meninas (FORTES et al., 2014). De acordo com os dados oriundos do questionário survey, dentre os participantes que responderam não gostar de seus corpos, as meninas foram maioria (22\% meninas e $5 \%$ meninos).

Segundo Fortes et al. (2014), um terço (1/3) da população jovem brasileira do sexo feminino sofre com algum tipo de insatisfação com a sua imagem corporal. Ainda de acordo com os autores, a mídia e a publicidade são as principais responsáveis por esse processo, pois transmitem imagens de corpos magros e atléticos associados à beleza e ao sucesso, que normalmente se distanciam da realidade das jovens, gerando sentimentos de descontentamento com a aparência física, forma corporal e peso.

A indústria da beleza e estética vê nos corpos femininos uma grande fonte de lucro, por isso criam revistas, sites, blogs, produtos e serviços voltados especificamente para o público feminino. Corpos são produzidos, modelados e remodelados, em um processo constante de ressignificação, sendo que todos os imperativos utilizados pela indústria da beleza e estética visam determinar o modo como as pessoas devem conduzir suas próprias vidas e como formar suas identidades (GOELLNER; FIGUEIRA, 2002) ${ }^{6}$. Segundo a estudante do grupo focal M.G. (16 anos): "Os padrões de beleza são fortemente impostos pela sociedade, de uma forma ou outra. Quando vemos um corpo 'escultural' e vemos que não temos igual ou parecido, isso acaba mexendo com nossa autoestima".

principal sintoma de desordem é o profundo desconforto - indecisão e irresolução - que sentimos quando somos incapazes de nos posicionarmos dentre as inúmeras possibilidades de escolhas presente em nosso cotidiano (BAUMAN, 1999).

${ }^{6}$ A beleza e a estética na sociedade contemporânea se tornaram um dever moral, sobretudo para as mulheres, elemento que talvez ajude a compreender o fato de $69 \%$ (amostra) das estudantes terem se interessado por nossa pesquisa, respondendo a nosso questionário e participando do grupo focal. 
Nesse sentido, pensando na lógica do consumo e de toda a insegurança, incerteza e desafios que se apresentam na juventude, é possível compreendermos o porquê de as adolescentes serem tão suscetíveis a estarem insatisfeitas com sua própria imagem corporal.

Contudo, quando nos atentamos para a relação dos participantes que afirmaram gostar de seus corpos, as meninas também são maior parte em termos percentuais quando comparadas aos meninos (47\% meninas e $26 \%$ meninos). Para analisar esse dado, utilizaremos à teoria baumaniana sobre os processos de individualização e privatização da vida presente na modernidade líquida ou sociedade contemporânea. De acordo com Bauman, o processo de "individualização" se constrói a partir da:

\begin{abstract}
Emancipação do indivíduo da determinação atribuída, herdada e inata do caráter social dele ou dela: uma separação corretamente vista como uma característica muito clara e seminal da sociedade moderna. Em resumo, a "individualização" consiste em transformar a "identidade" humana de uma coisa "dada" em uma "tarefa" - e encarregar os atores com a responsabilidade de realizar essa tarefa e de arcar com as consequências (e também com os efeitos colaterais) de seu desempenho; em outras palavras, consiste em estabelecer uma autonomia "de jure" (porém não necessariamente uma autonomia de facto). (2008b, p. 183).
\end{abstract}

A construção da identidade do sujeito na modernidade líquida não é fixa, Bauman (2008b) não fala em identidade, mas sim em identidades, pois, como já apontou o sociólogo, a liquefação do mundo contemporâneo impele o sujeito a se reinventar em diferentes fases da vida (estar em boa forma) ou escolher diferentes "caixas" feitas sob medida para a necessidade do momento. As "caixas" em vista:

\begin{abstract}
Apresentam vários tamanhos e estilos, com números mutáveis e posições móveis. Isso força homens e mulheres a estarem sempre se movendo, sem prometer descanso ou a satisfação de "chegar", não há consolo de chegar ao destino onde poderemos baixar os braços e relaxar. Não existe a possibilidade de um "reencaixe final" no fim da estrada; estar na estrada tornou-se o modo contínuo de vida dos indivíduos (agora cronicamente) desencaixados. (BAUMAN, 2008b, p. 186).
\end{abstract}

Nesse sentido, compreendemos que tanto as "caixas" ou movimentos que apresentam modos alternativos de viver o corpo feminino quanto as práticas pedagógicas associadas a elas podem auxiliar na (re)construção de um outro olhar sobre o corpo feminino. Ao questionarmos o grupo focal quanto à possível influência das aulas e dos projetos do CPII sobre alto número de estudantes que dizem gostar de seus corpos, as jovens responderam da seguinte forma:

Olha, eu não posso dizer que não existe nenhuma participação do Colégio nisso, tipo, que a gente está num ambiente muitíssimo diversificado, a gente tem contato com pessoas de realidades muito diferentes e com o debate muito 
diferente, justamente proporcionados não só pelas atividades acadêmicas oficiais, como as extraoficiais também, contatos que você tem com outras pessoas etc. (C.A., 15 anos).

É muito bom quando você assiste um documentário que você se reconhece e pode ver que existem diferentes tipos de corpos e que mesmo com as suas limitações todos podem ser eficientes e bonitos. Pra mim, que tenho um problema [nanismo], isso representou muito. (M.G., 16 anos).

Compreendemos com as respostas e reflexões apresentadas pelas estudantes, o quanto as atividades pedagógicas que abordam o corpo sob o olhar da diferença podem se constituir em espaços para ampliação das resistências e do cultivo de outras experiências de "liberdade" dos indivíduos - convidando-os a tornar seus percursos biográficos (construção de suas identidades corporais) um projeto reflexivo (BAUMAN, 2008b).

Após perguntar aos estudantes se gostavam de seus corpos, passamos a questioná-los sobre os motivos que os levavam a gostar ou não deles. Quanto a essa questão, os resultados apontaram para alguns padrões nas respostas dos estudantes, como estar confortável e se sentir bem, estar com boa saúde, estar acima do peso e fora dos padrões corporais veiculados pela mídia de massa.

No que tange ao grupo que afirmou gostar do próprio corpo no questionário survey, os sentidos mais atribuídos por eles dizem respeito a sentirem-se confortáveis com ele, por exemplo: "Porque eu me sinto completamente confortável nele e não mudaria nada" (D.T., 16 anos); "Porque não há nada que me incomode ou que eu queira mudar" (C.B., 15 anos); "Me sinto bem ao olhar meu corpo" (M.M., 18 anos); "Porque ele combina comigo" (G.A., 16 anos).

A saúde também esteve presente nos discursos de alguns dos estudantes para justificarem o motivo de gostarem de seus corpos: "Porque não há nada de errado com ele, como uma doença ou lesão" (A.C., 15 anos); "Estou com boa saúde” (M.B., 19 anos); "Estou satisfeita porque acho que ele é um corpo adequado para minha idade. Tenho saúde e me sinto bem com ele" (J.M., 17 anos).

As respostas dos estudantes que afirmaram no questionário que não estão satisfeitos com seus corpos estão mais direcionadas ao campo da estética, principalmente para questões relacionadas ao peso corporal e a estar fora dos padrões corporais veiculados pela mídia de massa: "Porque eu estou muito acima do meu peso normal" (D.T., 18 anos); "Falta perder um pouco de barriga" (L.S., 18 anos); "Não me sinto bem por ser magra demais e, por isso, sofro bulliyng às vezes." (A.N., 17 anos); "Sou gordo e tenho vergonha" (H.F., 17 anos) "Não me 
sinto confortável expondo, não acho atraente aos meus próprios olhos (apesar de defender a body positivity $^{7}$ e pregar que todos os corpos são bonitos)" (M., 16 anos).

A sensação de estar fora dos padrões produzidos e veiculados pela mídia de massa marca os discursos apresentados, e as falas estão carregadas de insegurança, medo e vergonha, características apontadas pela teoria baumaniana para caracterizar o sentimento dos sujeitos que estão à margem do imaginário de corpo presente na sociedade de consumidores. Não ter o corpo dentro dos padrões estéticos estabelecidos mexe com a autoestima de uma parcela dos estudantes pesquisados, mesmo aqueles que pregam a body positivity e compreendem que a beleza dos corpos está na diferença.

Depois de responderem se gostam ou não dos seus corpos, os estudantes foram questionados sobre como se sentem quando se olham no espelho (Inseguro, 32\%; Infeliz, 8\%; Ansioso, 4\%; Seguro, 22,7\%, Feliz, 24\% e Outro, 9,3\%).

Se somarmos os resultados das opções que mostram o estado de satisfação com o corpo (feliz, $24 \%$ e seguro, $22,7 \%$ ), veremos que $46,7 \%$ dos estudantes se sentem felizes e seguros quando se olham no espelho. Para a estudante do grupo focal A.C. (16 anos), o CPII contribui de maneira positiva no sentido de minimizar potenciais problemas relacionados ao corpo dos estudantes: "Eu acho que aqui no Colégio batem muito na tecla de você se aceitar e ajuda muito a nós, estudantes. Sei lá, eu acho um pouco menos agressiva a questão do corpo aqui dentro do Colégio". Na mesma direção, o estudante do grupo focal M.S. (18 anos) complementa: "Sim, até porque o Colégio favorece muito isso, não é? Eu vejo assim. Pelo menos nunca vi um Colégio tão aberto a essas questões, seja LGBT ou questões de corpo ou qualquer outra questão". O que se destaca na fala dos estudantes é o compromisso do CPII com a diferença, ou seja, o ensino se baseia na premissa de que todos os estudantes são diferentes e plurais em cada dimensão que compõe suas identidades e modos de vida.

Segundo Bracht (2013, p. 111-112), o corpo consumidor ou contemporâneo se desloca do "asceticismo para o hedonismo, ou então uma melhor convivência entre os dois; do corpo produtivo ao corpo consumidor; do corpo dócil para o corpo flexível". Enfim, o corpo passa a ser visto como fonte de prazer, ganhando as sensações corporais o status de finalidade e sentido de viver (BRACHT, 2013). Em suma, a cultura contemporânea "confere ao corpo um novo status social e ontológico, portanto, um novo papel na construção das subjetividades ou

\footnotetext{
${ }^{7}$ A organização Body Positive foi fundada em 1996 por Connie Sobczak e Elizabeth Scott. A organização tem como essência a valorização da identidade e da beleza única de cada pessoa, respeitando a diferença, sobretudo com relação ao corpo.
} 
identidades. Isso significa, admitirmos a necessidade de uma ressignificação da corporeidade humana" (BRACHT, 2013, p. 112).

Portanto, o desafio que se lança à educação relacionada ao corpo na sociedade contemporânea passa, então, pelo reconhecimento das diferenças sem, contudo, prescindir do pensamento sobre os distintos modos de ser e estar no mundo, afinal "essa abertura aos outros é precondição para uma humanidade diferente, e a escola, está é a expectativa, pode e deve tomar parte nisso" (ALMEIDA; BRACHT; GOMES, 2009, p. 58). Para Bauman (2007a, p. 164), o imperativo mais importante da atual configuração do discurso da educação é "tornar esse mundo em rápida mudança mais hospitaleiro para a humanidade". A finalidade da educação nesse caso, seria “contestar o impacto das experiências do dia a dia, enfrentá-las e por fim desafiar as pressões que surgem do ambiente social" (BAUMAN, 2007a, p. 21) - o que nos prece ser o caso do CPII.

Se compararmos ao resultado da pergunta inicial sobre gostar ou não do corpo, em que $73 \%$ responderam que sim, gostam do seu corpo, veremos que há uma margem de $26,3 \%$ (que responderam gostar de seus corpos) de estudantes que não se sentem felizes ou seguros com seus corpos, o que, de certa maneira, revela que gostar do corpo não necessariamente está associado a estar satisfeito com ele para essa parcela dos estudantes da pesquisa. Ainda sobre esses dados, parece-nos, assim como para C.A. (15 anos) - "De qualquer forma, eu me surpreendo porque muita gente diz que sim (sobre gostar do próprio corpo), mas não é isso que a gente vê aí fora. E eu acho que isso acontece porque muitas pessoas têm vergonha de dizer que não estão satisfeitas com seu corpo" -, que uma parcela dos estudantes possui certa dificuldade em dizer que não gosta dos seus corpos, pois, ao mesmo tempo que 46,7\% dizem gostar de seus corpos e se sentem felizes e seguros quando se olham no espelho, $44 \%$ se dizem infelizes, insatisfeitos e/ou inseguros com relação ao que vê no espelho, e isso inclui parte dos $26,3 \%$ dos estudantes que disseram gostar de seus corpos inicialmente.

O depoimento de C.A. (15 anos) nos ajuda a compreender o motivo de esses jovens não se sentirem confortáveis ao se olharem no espelho. Afinal, para ela, "O principal motivo das pessoas sentirem incômodo com o próprio corpo é que elas não se veem representadas", muito em função do tipo de corpo produzido e veiculado pelos diferentes meios de comunicação, o que pode indicar uma forte influência da indústria da beleza e estética na vida dessa parcela de jovens da pesquisa.

Dessa forma, mesmo convivendo em um ambiente diversificado e que proporcione reflexões acerca das questões que envolvem o corpo, os estudantes do CPII não estão livres das questões que cercam a estética corporal, como nos apresenta a estudante do grupo focal L.M. 
(19 anos): "Durante as aulas na piscina, muita gente deixa de fazer porque tem vergonha de colocar a sunga, tem vergonha de colocar o maiô, ou, às vezes, tem vergonha de trocar de roupa no vestiário com os próprios amigos de sala”.

Esses depoimentos reforçam toda a ambivalência e fluidez que ora dominam as questões corporais no mundo contemporâneo. Por outro lado, a pesquisa tem nos mostrado que existe um grupo de estudantes $(46,7 \%)$ que diz gostar e que também se sentem felizes e seguros em relação ao seus corpos, apesar de toda a pressão e regulação que sofrem. Para Bauman (2001, 2010), nossos corpos flutuam entre a posição de objetos de desejo (felicidade e orgulho) e a de fontes de tristeza e vergonha. Ainda segundo o autor, o amor de si (visto como responsabilização individual e autocuidado sobre o corpo) como um imperativo construído por meio da relação dialógica a partir de nossos contextos sociais e culturais - que forma quem somos e quem viremos a nos tornar - nos dá a sensação de "[...] definir o que poderá ser fonte de conforto, mas também algo para se resistir em sua invocação das normas que reprimem a diferença [ou as diferentes identidades corporais]" (BAUMAN, 2010, p. 173).

Outro ponto que se destaca nos resultados é a compreensão das questões corporais em relação à renda dos estudantes, pois, dos $46,7 \%$ dos estudantes que afirmam que se sentem felizes e seguros quando se olham no espelho, 2,7\% estão dentro do grupo com renda familiar de um ( $\mathrm{R} \$ 880,00)$ salário mínimo, 38,7\% dentro da faixa de renda de um ( $\mathrm{R} \$ 880,00)$ a três ( $\mathrm{R} \$ 2.640,00)$ salários mínimos e 5,2\% estão dentro da faixa de renda de três ( $\mathrm{R} \$ 2.640,00)$ a seis ( $\mathrm{R}$ 5.280,00) salários mínimos, enquanto que, dos 44\% dos estudantes que se disseram inseguros, infelizes e ansiosos, 10,7\% estão dentro do grupo com renda familiar de três $(\mathrm{R} \$ 2.640,00)$ a seis $(\mathrm{R} \$ 5.280,00)$ salários mínimos, $18,7 \%$ de seis $(\mathrm{R} \$ 5.280,00)$ a nove ( $\mathrm{R} \$ 7.920,00)$ salários mínimos, 6,7\% de nove $(\mathrm{R} \$ 7.920,00)$ a doze $(\mathrm{R} \$ 10.560,00)$ salários mínimos e $8 \%$ mais de doze $(\mathrm{R} \$ 10.560,00)$ salários mínimos.

Dessa maneira, o cruzamento das informações nos mostra que os estudantes que se sentem mais felizes e seguros com seus corpos estão inseridos dentro de uma faixa de renda baixa a média baixa, enquanto os estudantes que se sentem mais inseguros, infelizes e ansiosos se inserem em uma faixa de renda média baixa a média alta.

Segundo Silva (2001), os indivíduos que parecem estar mais vulneráveis e suscetíveis aos apelos do mercado do corpo, em geral, são jovens e pertencentes a famílias de classe média e alta (como nas falas apresentadas abaixo), ou seja, a insatisfação corporal para esse grupo de estudantes parece crescer à medida que os sujeitos têm mais acesso aos bens e serviços voltados para o mercado do corpo. 
A famosa barriga chapada, pernas um pouco grossas, seios e glúteos de um tamanho médio e sem marcas. (M.G., 16 anos).

Um corpo nem muito magro, nem muito acima do peso, um corpo que a massa muscular acrescente tamanho e formas bonitas, mas sem exagero. (J.M., 17 anos).

Bustos na medida correta, barriga chapada, bumbum empinado e coxas grossas. (I.L., 16 anos).

Nesse sentido, “[...] as relações que o mercado estabelece com a expectativa de corpo predominante na atualidade são múltiplas, criando sempre demandas corporais e novas exigências aos indivíduos modernos" (SILVA, 2001, p. 59), dando aos possíveis consumidores um supermercado de opções que visam aos cuidados do corpo ininterruptamente. Talvez resida nesse fato a correlação entre renda e acesso ao consumo para justificar os sentimentos de insegurança, infelicidade e ansiedade no que tange ao corpo para esse grupo de estudantes, pois, de acordo com Silva (2001) e Bauman (2011), a sociedade contemporânea se movimenta a partir das necessidades/desejos/vontades dos consumidores, sempre crescentes e renovadas.

Por outro lado, não queremos aqui afirmar que os estudantes do estudo pertencentes às classes baixa e média baixa não se importam com os cuidados com o corpo ou não se sintam insatisfeitos com seus corpos, até por que, em pesquisa realizada com jovens escolares de classes populares de Vitória/ES, Braga, Molina e Figueiredo (2010) apontam que, apesar de pertencerem a uma classe socioeconômica menos favorecida, os estudantes demonstraram estar preocupados com a estética corporal e interessados nos modos de viver os corpos hegemônicos, compartilhados a partir da lógica do consumo, ou seja, o que queremos apresentar é que, de alguma forma, os estudantes de renda baixa e média baixa deste estudo possuem modos de viver o corpo que se diferenciam do grupo anterior, como nas falas apresentadas a seguir:

A pessoa deve se sentir feliz com seu corpo independentemente de como for. Para mim, não existe padrão de beleza. (B.A., 18 anos).

Depende de cada um de nós, tem quem ache bonito pernas grossas, outros finas, o que importa é você buscar de maneira saudável o "SEU" corpo ideal, não o corpo que alguém além de você diga ser bonito. (B.C., 16 anos).

Para explorarmos um pouco mais essa questão, perguntamos aos estudantes se, na visão deles, existira um modelo de corpo perfeito. De acordo com as respostas dos estudantes a essa questão, 21,3\% afirmam que existe e 78,7\% responderam que não existe. Apresentamos esse resultado aos estudantes que participaram do grupo focal e pedimos a eles para que os interpretasse. 
Quando consultados, os estudantes participantes do grupo focal não se surpreenderam com os dados. Para eles, o ambiente diversificado (social, político, econômico, cultural e de gênero etc.) e o acesso a conhecimentos relacionados ao corpo proporcionados pelas disciplinas e outros espaços de discussão e reflexão no CPII contribuem para o olhar mais apurado dos estudantes sobre as questões que envolvem corpo na sociedade contemporânea. Além disso, a estudante T.S. (19 anos) faz uma provocação: "Talvez não exista o corpo perfeito. Porque, se está todo mundo querendo melhorar o corpo, qual é o corpo perfeito?”. A fala da estudante reforça o entendimento sobre a busca pela boa forma na sociedade de consumidores. Segundo Bauman (2001, p. 81), “[...] na corrida dos consumidores, a linha de chegada sempre se move mais veloz que o mais veloz dos corredores".

Os estudantes que responderam "sim, existe um corpo perfeito" foram questionados se haveria um limite para a busca dele. Os resultados foram apresentados para os estudantes do grupo focal que teceram algumas reflexões sobre as respostas dos estudantes presentes no questionário survey sobre esse tema. Os discursos dos estudantes sobre ter ou não limite para a busca pelo corpo desejado se situam, sobretudo, no campo do excesso:

Às vezes, quando nos preocupamos e buscamos excessivamente um corpo perfeito através de intervenções cirúrgicas, por exemplo. (J. M., 17 anos).

Acho que o limite seria quando a busca por ele se torna obsessão, causando mais danos ao corpo que benefícios. (B.C., 16 anos).

Assim como no questionário survey, as reflexões dos estudantes do grupo focal se situaram no campo do excesso, que logo se transforma em obsessão e vício (BAUMAN, 2011), e se materializam em intervenções no corpo, dietas e exercícios físicos que, muitas vezes, desaguam em um processo de deterioração da saúde, como patologias relacionadas à alimentação, dentre elas a bulimia e a anorexia.

Para as estudantes do grupo focal M.G. (16 anos) e A.C. (16 anos), o que mais chama a atenção são os exageros cometidos em intervenções cirúrgicas, como as cirurgias plásticas. Segundo a estudante A.C. (16 anos): “A pessoa perde as suas características e parece que nasceu de novo como outra pessoa, você vai se transformando e perdendo sua identidade." Pensando a partir da lógica do consumo, a busca por um corpo "perfeito" é um eterno jogo de tentativas e erros (BAUMAN, 2007), como na fala das estudantes:

É um círculo vicioso. Quando você acha perfeito, aí aparece uma coisinha que você quer mudar, e nisso acaba aparecendo um produto novo que diz que vai melhorar aquilo e você compra esse produto. Aí vai surgindo outro e outro e outro... porque o mercado é assim, quando ninguém quer mais comprar, surge 
um novo produto que diz que vai melhorar ainda mais, você vai comprando, vai comprando, vai comprando. (L.M., 19 anos).

Você nunca está satisfeita com o que você tem e aí tem sempre alguém falando que você não pode estar satisfeita, que você não está certa do jeito que você está. Então, é isso, é a mídia, são as pessoas, a gente tem uma cultura que é assim, que é sempre de criticar o que a gente tem, porque você não pode estar satisfeita com o que você é, você tem que estar sempre melhor, do que eles acham que seja o melhor. (T.S., 19 anos).

Segundo Lima et al. (2013), saímos de um período de satisfação administrada que pode ser compreendida dentro do que Bauman (2001) convencionou chamar de modernidade sólida (produtores) para um período de insatisfação administrada na modernidade líquida (consumidores). Administrar a insatisfação das pessoas é característica importante da sociedade contemporânea, pois, para Bauman (2007), a insatisfação permanente é o que move a sociedade de consumidores. Os casos de excesso, sobretudo com relação a dietas, procedimentos estéticos e exercícios físicos, estão presentes na maioria das respostas e falas dos estudantes, o que evidencia o tom crítico dos jovens do CPII sobre o mecanismo da insatisfação administrada na sociedade de consumidores.

\section{RELAÇÕES ENTRE CORPO E MÍDIA SEGUNDO A PERCEPÇÃO DOS ESTUDANTES DO CPII}

Faremos uma breve incursão em um dos pontos que mobilizou as discussões dos estudantes participantes desta pesquisa que foi a influência das mídias sobre as representações de corpo. Acerca dessa temática, questionamos os estudantes se a mídia de massa (programas, comerciais, sites e blogs sobre saúde, estética, dieta e estilos de vida saudável) influencia em suas decisões de consumo no que tange ao corpo. De acordo com as respostas dos alunos, 78,7\% disseram que sim, enquanto $21,3 \%$ responderam não.

Sobre essa temática, Goellner e Figueira (2002) dizem que a mídia assume importante papel na construção da identidade do adolescente, a partir de um processo chamado de pedagogia cultural. De acordo com as autoras, as mídias, por meio de diferentes estratégias, exercem sobre os jovens um grande poder, no sentido de educá-los no que diz respeito à construção de um corpo jovem, moderno e saudável (GOELLNER; FIGUEIRA, 2002). Goellner e Figueira (2002) apresentam questões muito próximas da teoria baumaniana sobre o papel do corpo na sociedade contemporânea, pois ele, o corpo, assume papel central na construção das identidades dos sujeitos (BAUMAN, 2011). Essas identidades, em muitos casos, 
são forjadas a partir de modelos de corpos ideais, produzidos e transformados sob as demandas do mercado.

Nos dados produzidos em nossa pesquisa, identificamos que os estudantes acreditam que as diferentes mídias exercem poder sobre as decisões de consumo dos jovens, bem como a construção de "corpos ideais" que servem apenas como vetor de insatisfação, insegurança e ansiedade nos sujeitos que vivem na sociedade contemporânea.

Não tem como não influenciar. Somos de uma geração que já nasceu vendo televisão ou usando celular. Somos de uma geração que tem a difícil tarefa de filtrar tudo o que consumimos pela mídia; se aquela informação é verdadeira, se tem algum interesse político escondido, se realmente tem aquele resultado, se faz bem, se está prejudicando outros etc. Apesar de nós, estudantes do CPII, termos a consciência da necessidade dessa filtragem, procurarmos ao máximo não cair nessa cadeia de produção de consumidores, ainda somos influenciados de alguma forma. (L.S., 18 anos).

É óbvio que a mídia possui forte influência em qualquer esfera de nossas vidas, principalmente se tivermos vínculos diretos a ela - TV, rádio, Internet etc. Essa consegue criar a sensação de vazio que somente pode ser saciado com produtos, dando início, assim, ao consumismo desnecessário e irracional. Vivemos em uma sociedade capitalista que se mantém pela exploração e resultando na acumulação de bens para quem já possuem. E a mídia tem um papel fundamental nesse sistema, pois os meios de comunicação são as formas mais próximas e fáceis de chegar na população. (S.C., 17 anos).

Apresentaremos a seguir as poucas falas dos estudantes que responderam no questionário survey que a mídia não influência em suas decisões de consumo.

Eu quase não assisto propagandas, e quando assisto, em sua maioria, eu não acredito na qualidade do produto ou creio que não vá ter realmente algum efeito relevante. (C.B., 17 anos).

Não, pois, por mais que a mídia influencie as pessoas com técnicas de marketing, tenho um grande conhecimento sobre alienação das mídias nas minhas aulas de Sociologia e, por isso, não sou mais alienada. Porém, muitas pessoas não têm conhecimentos básicos sobre esses assuntos. (A. N., 17 anos).

As duas falas, que nos ajudam a refletir sobre a questão, situam-se no campo da formação do estudante no CPII. As falas estão ancoradas no processo de reflexão, porque, para os estudantes, é necessário estabelecer um filtro sobre as informações emitidas pela mídia, pois, mesmo entendendo que há necessidade de filtrar as informações, acabamos nos influenciando pela maneira sutil e dialógica com que as relações entre os adolescentes, a cultura e a mídia de massa são construídas e estabelecidas.

De acordo com as falas dos estudantes, podemos chegar a duas considerações: a primeira, a de que os estudantes entendem e sabem que existe uma força e um poder presente 
em diferentes estratégias midiáticas que tentam guiar nossas vidas e influenciar nossas escolhas, ou seja, os estudantes do CPII possuem criticidade, o que tem se revelado ao longo do nosso trabalho. A segunda refere-se ao fato de que os estudantes também sabem que, mesmo com uma formação - como a do CPII - voltada para o questionamento e reflexão sobre as questões relacionadas ao consumo ninguém está imune às pressões exercidas pela indústria da beleza, o que na teoria baumaniana se configura pela pragmática do comprar, exercida dentro da lógica neoliberal na sociedade de consumidores (BAUMAN, 2001).

\section{CONSIDERAÇÕES FINAIS}

No presente artigo, apresentamos e analisamos as representações corporais de um grupo de 77 estudantes do Ensino Médio do Colégio Pedro II - Campus São Cristóvão III. O primeiro tópico analítico mostrou-nos que existe um grupo de estudantes que construíram suas identidades corporais em torno de uma compreensão de corpo mais ampliada e crítica, alinhada com a pluralidade e a diversidade. Além disso, também foi destaque o alto número de meninas que dizem gostar e estar felizes e seguras com seus corpos, resultado diferente de alguns artigos que tratam de temáticas similares (ANDRADE et al., 2007; PALMA et al., 2013; FORTES et $a l ., 2014)$. Outro aspecto importante e que reforça os anteriores foi o elevado índice de estudantes que disseram não haver um modelo de corpo perfeito. Nos três casos, os estudantes chamam atenção para a participação e possível contribuição do CPII no processo de problematização, ressignificação e (re)construção de identidades corporais mais plurais.

No entanto, o estudo também nos mostrou que mesmo convivendo em um ambiente plural e diverso, onde a temática do corpo é apresentada de maneira reflexiva, os estudantes do CPII não estão imunes às incertezas e medos provocados pelas questões que cercam a estética corporal na sociedade de consumidores. Esses dados reforçam toda a ambivalência e fluidez que ora dominam as questões corporais na modernidade líquida.

No último tópico de análise, o discurso midiático foi apontado pelos estudantes como a principal via de produção e veiculação de um determinado tipo de corpo, que influencia e/ou potencializa os processos de insatisfação corporal, assim como destacaram que a mídia possui forte influência em suas decisões de consumo. Por outro lado, os estudantes também sabem que, mesmo com uma formação voltada para o questionamento e reflexão, como a do CPII, não ficam alheios às pressões da indústria do corpo.

Por isso, a escola, em tempos de modernidade líquida, deveria se constituir num tempo/espaço aberto à pluralidade e à multiplicidade de significados das muitas culturas, 
valores plurais e identidades culturais presentes na sociedade que chegam até ela (BAUMAN, 2002). Isso significaria que os estranhos - os diferentes e as minorias (sejam elas étnicas, religiosas, raciais e de gênero etc.), outras vezes tidos como presença indesejável - poderiam ter novas oportunidades nesse modelo de escola, não mais com a tal ojeriza à diversidade, à diferença e à ambivalência que fizeram da escola uma instituição responsável pelo controle social em diferentes períodos. Entendemos, assim como Bauman (2008b), que o processo para a construção de uma escola que seja capaz de enfrentar os desafios postos pela modernidade líquida será uma tarefa:

Desconhecida e desafiante, de teorizar um processo formativo que não está guiado desde o começo por uma forma selecionada como objetivo e selecionada como antecipação; de modelar sem que o modelo que se quer se conheça nem veja com claridade; um processo que pode esboçar seus resultados, sem nunca impô-los, e que integra essa limitação em sua própria estrutura; em suma, um processo aberto, mais preocupado em seguir aberto que por qualquer produto concreto e que teme mais a toda conclusão prematura que a possibilidade de permanecer sempre sem conclusão. (BAUMAN 2008b, p. 159).

Nesse trecho, o autor nos convida a pensar a escola na atualidade de maneira que a ordem, a rotina e o "sempre mesmo", que antes caracterizava a escola (ALMEIDA; BRACHT; GOMES, 2009), dê lugar à pluralidade, à diferença e à diversidade de sujeitos, de culturas, de formas de vida, de pensar e de se expressar corporalmente, modificando práticas pedagógicas historicamente ancoradas pela padronização e exclusão das diferentes identidades que compõem o ambiente social, cultural e escolar brasileiro. Nessa direção, em meio às tensões e conflitos que envolvem as instituições escolares, o estudo nos mostrou, em diferentes momentos, as possiblidades que o Colégio Pedro II ofereceu para a (re)construção de identidades corporais plurais em espaços de práticas pautadas pela problematização, reflexão e ressignificação sobre os saberes relacionados ao corpo.

\section{REFERÊNCIAS}

ALMEIDA, Felipe Quintão de; BRACHT, Valter; GOMES, Ivan Marcelo. Bauman \& a educação. Belo Horizonte: Autêntica, 2009.

ANDRADE, Mônica Rodrigues Maia et al. Prevalência de (in)satisfação corporal em escolares do Ensino Médio. In: SEMINÁRIO NACIONAL DE CORPO E CULTURA, 1., 2007, Vitória. Anais... Universidade Federal do Espírito Santo, 2007. 
BAUMAN, Zigmunt. Vida em fragmentos: sobre a ética pós-moderna. Rio de Janeiro: Jorge Zahar, 2011.

Aprendendo a pensar com a sociologia. Rio de Janeiro: Jorge Zahar, 2010.

. Vida para consumo: a transformação das pessoas em mercadoria. Rio de Janeiro, Jorge Zahar, 2008a.

A sociedade individualizada: vidas contadas, histórias vividas. Rio de Janeiro: Jorge Zahar, 2008b.

Vida Líquida. Rio de Janeiro: Jorge Zahar, 2007.

Desafios educacionais na Modernidade Líquida. Revista Tempo Brasileiro, Rio de Janeiro, n. 148, p. 41-58. jan./mar. 2002.

Modernidade Líquida. Rio de Janeiro: Jorge Zahar, 2001.

Os livros no diálogo global das culturas. Revista Tempo Brasileiro, Rio de Janeiro, n. 142 , p. 87-101, jul./set. 2000.

Modernidade e ambivalência. Rio de Janeiro: Jorge Zahar, 1999.

BRACHT, Valter. A Educação Física brasileira e a crise da década de 1980: entre a solidez e a liquidez. In. MEDINA, Jõao. P. S. (orgs.). A educação Física cuida do corpo... e "mente". $26^{\mathrm{a}}$ ed. Campinas, SP: Papirus, 2013, p. 99-116.

BRAGA, Patrícia Déa; MOLINA, Maria del Carmen Bisi; FIGUEIREDO, Túlio Alberto Martins de. Representações do corpo: com a palavra um grupo de adolescentes de classes populares. Ciência \& Saúde Coletiva, n. 15, p. 87-95, jan. 2010.

DAYRELL, Juarez Tarcisio (org.) Juventude e Ensino Médio: sujeitos e currículos em diálogo. Belo Horizonte: Editora UFMG, 2014.

O jovem como sujeito social. Revista brasileira de educação, Rio de janeiro, n. 24, p. 40-52, set./out./nov./dez. 2003.

FORTES, Leonardo de Sousa et al. A autoestima afeta a insatisfação corporal em adolescentes do sexo feminino? Revista Paulista de Pediatria, São Paulo, v. 32, n. 3, p. 236$240,2014$.

GOMES, Romeu. Análise e interpretação de dados de pesquisa qualitativa. In. MINAYO, Maria Cecília de Souza. (org.). Pesquisa social: teoria, método e criatividade. Petrópolis: Vozes, 2009, p. 79-108.

GOMES, Romeu et al. Organização, processamento, análise e interpretação de dados: o desafio da triangulação. In. MINAYO, Maria Cecília de Souza; ASSIS, Simone Gonçalves de; SOUZA, Edinilsa Ramos de (orgs.). Avaliação por triangulação de métodos:

abordagem de programas sociais. Rio de Janeiro: Fiocruz, 2005, p. 185-221. 
GOELLNER, Silvana Vilodre.; FIGUEIRA, Márcia Luiza Machado. Corpo e Gênero: a revista capricho e a produção do corpo feminino. Motrivivência, Florianópolis, n. 19, ano XIII, p. 1-13, dez. 2002.

LIMA, Aluísio Ferreira de; BATISTA, Karina de Andrade; LARA JUNIOR, Nadir. A ideologia do corpo feminino perfeito: questões com o real. Psicologia em Estudo, Maringá, v. 18, n. 1, p. 49-59, jan./mar. 2013.

MARQUES, Inês Maria et al. (In)Satisfação com a imagem corporal na adolescência. Nascer e Crescer, Porto, v. 25, n. 4, p. 217-221, 2016.

MINAYO, Maria Cecília de Souza. O desafio do conhecimento: pesquisa qualitativa em saúde. São Paulo: Hucitec, 2006.

PALMA, Alexandre et al. A insatisfação com peso e massa corporal em estudantes do ensino médio do sexo feminino no Município do Rio de Janeiro. Revista Brasileira de Ciências do Esporte, Florianópolis, v. 35, n. 1, p. 51-64, jan./mar. 2013.

PASSOS, Michelle Delboni dos et al. Representações sociais do corpo: um estudo com adolescentes do Município do Rio de Janeiro, Brasil. Cadernos de Saúde Pública, Rio de Janeiro, v. 29, n. 12, p. 2383-2393, dez. 2013.

PERALVA, Angelina. O jovem como modelo cultural. Revista Brasileira de Educação, São Paulo, n. 5/6, p. 15-24, 1997.

PAIS, José Machado. Culturas juvenis. Lisboa: Imprensa Nacional/Casa da Moeda, 1993.

RICHARDSON, Roberto Jarry. Pesquisa social: métodos e técnicas. 3. ed. São Paulo: Atlas, 1999.

SILVA, Ana Márcia. Corpo, ciência e mercado: reflexões acerca da gestão de um novo arquétipo de felicidade. Campinas, SP: Autores Associados, 2001.

TRAD, Leny Alves Bomfim. Grupos focais: conceitos, procedimentos e reflexões baseadas em experiências com o uso da técnica em pesquisas de saúde. Physis Revista de Saúde Coletiva, Rio de Janeiro, v. 19, n. 3, p. 777-796, 2009.

WALTER, Olga Maria Formigone Carvalho. Análise de ferramentas gratuitas para condução de survey online. Produto e Produção, Porto Alegre, v. 14, n. 2, p. 44.58, jun. 2013.

\section{SOBRE OS AUTORES:}

\section{Guilherme de Castro Ribeiro Ferreira e Silva}

Mestre em Educação Física, Universidade Federal do Espírito Santo (UFES); Professor do Colégio Pedro II (CPII) - Brasil; Membro do Grupo de Estudos e Pesquisas em Educação Física Escolar (GEPEFE/CP2). E-mail: guilherme.ef.cp2@gmail.com

(iD https://orcid.org/0000-0002-1963-3276 


\section{Ivan Marcelo Gomes}

Doutor em Ciências Humanas, Universidade Federal de Santa Catarina (UFSC); Professor do Centro de Educação Física e Desportos da Universidade Federal do Espírito Santo - Brasil; Professor do Programa de Pós-Graduação em Educação Física da Universidade Federal do Espírito Santo; Membro do Laboratório de Estudos em Educação Física (LESEF/UFES). Email: ivanmgomes@ hotmail.com

(iD) https://orcid.org/0000-0002-0311-9651

\section{Leonardo Trápaga Abib}

Doutor, UFES; Universidade Federal do Espírito Santo - Brasil; Laboratório de Estudos em Educação Física (LESEF). E-mail: leoabib@ gmail.com

iD https://orcid.org/0000-0001-9335-2141 